\title{
Prevalence of muscular dystrophy in patients with muscular disorders in Tehran, Iran
}

\author{
Khadijeh Haji Naghi Tehrani (1), Maliheh Hajiloo (2), Elham Asadollahi (2), Fariba \\ Paydar Lagini (2)
}

(1) Department of Neurology, Islamic Azad University Tehran Medical Science Branch Tehran; (2) Faculty of Medicine, Tehran Medical Branch, Islamic Azad University, Tehran, Iran

This article is distributed under the terms of the Creative Commons Attribution Noncommercial License (CC BY-NC 4.0) which permits any noncommercial use, distribution, and reproduction in any medium, provided the original author(s) and source are credited.

\begin{abstract}
Muscular dystrophy is a group of diseases that is characterized by progressive muscle wasting and the weakness of variable distribution and severity. On the basis of the distribution of predominant muscle weakness, there are many different kinds of muscular dystrophy. Some dystrophies are especially frequent in certain populations. There are no studies on the prevalence of muscular dystrophy in Iran. This study was aimed to survey the prevalence of muscular dystrophy among Iranian patients with muscular disorders. This analytical cross-sectional study was conducted on 1000 patients with musculoskeletal disorders who visited the dystrophy association of Bou-Ali Hospital (Tehran) from June 2014 to June 2016. Patients' data were extracted using a checklist that included age, gender, age of onset, family history, findings from clinical diagnostic tests and types of muscular dystrophy. The clinical findings were the results of genetic tests; EMG-NCV; para-clinical findings, including LDH and CPK; and pathological findings. All data were analyzed by SPSS V.22 (IBM Inc., NY) with Chi Square and One way ANOVA tests. All analyses were performed with $\mathrm{P}=0.05$ considered as the threshold of statistical significant. Out of the 337 patients studied, $262(77.7 \%)$ were male and $75(22.3 \%)$ were female. Subjects had a mean $( \pm$ SD) age of $26.08( \pm 11.86)$ years with an age range of 3 to 59 years. The most common types of muscular dystrophy were found to be Duchenne dystrophy (131 cases, 38.9\%), limb-girdle dystrophy (91 cases, 27\%), Becker dystrophy (58 cases, 17.2\%), FSHD dystrophy (31 cases, 9.2\%), and SMA (26 cases, 7.7\%), respectively. The results showed that a statistically significant relationship between dystrophy types and gender, age, family history, age of diagnosis, CPK and LDH levels $(\mathrm{P}<0.001)$. There were no statistical relationship between dystrophy types and pathological findings $(\mathrm{P}=0.57)$, EMG-NCV test results $(\mathrm{P}=$ $0.062)$, and genetic findings $(\mathrm{P}=0.06)$. Since muscular dystrophies often appear during the first decade of life, any information in regard to their prevalence can contribute to better planning and provisioning of required services, as well as better treatment or control of the condition. The results also showed that genetic tests, para-clinical tests, pathology analysis, and EMG-NCV tests can serve as good diagnostic tools for different varieties of dystrophy. Thus, facilitation of these diagnostic tests, particularly the genetic tests, can lead to a faster and more accurate diagnosis of dystrophy, especially in people with a family history of the disease.
\end{abstract}

Key Words: Prevalence, Muscular Dystrophy, Muscular Disorders, Iran.

Eur J Transl Myol 28 (2): 220-225, 2018

Muscular dystrophy is a group of diseases that is characterized by progressive muscle wasting and the weakness of variable distribution and severity. In muscular dystrophy, abnormal genes (mutations) interfere with the production of the proteins needed to form healthy muscle. ${ }^{1,2}$ On the basis of the distribution of predominant muscle weakness, there are many different kinds of muscular dystrophy, including congenital forms:
Duchenne and Becker; Emery-Dreifuss; distal; facioscapulo-humeral; oculopharyngeal; spinal muscular atrophy (SMA), and limb-girdle, which is the most heterogeneous group. ${ }^{3,4}$ The main sign of muscular dystrophy is progressive muscle weakness. Specific signs and symptoms begin at different ages and in different muscle groups, depending on the type of muscular dystrophy. In Duchenne muscular dystrophy, onset is in 
early childhood. Signs and symptoms typically appear between the ages of 2 and 3 and may include frequent falls, difficulty getting up from a lying or sitting position, trouble running and jumping, muscle pain and stiffness, and learning disabilities. ${ }^{5-7}$ In Becker muscular dystrophy, signs and symptoms are similar to those of Duchenne muscular dystrophy, but are typically milder and progress more slowly. In other types of muscular dystrophy, signs can vary and may include the inability to relax muscles (myotonic), muscle weakness in the face and shoulders (Facioscapulohumeral or FSHD), and may affect hip and shoulder muscles (limb-girdle) ${ }^{8-16}$ On the basis of some studies, incidence at birth of Duchenne muscular dystrophy is around $300 \times 10^{-6}$, and its prevalence in the population (in terms of the total male population) is around $60 \times 10^{-6}$. Also, based on a detailed study from Sweden, the prevalence of muscular dystrophy in children under the age of 16 years was estimated to be $25 \times 10^{-6}$ for congenital muscular dystrophy, $8 \times 10^{-6}$ for limb-girdle muscular dystrophy, $8 \times 10^{-6}$ for FSHD muscular dystrophy, and (only in boys) $16 \times 10^{-6}$ for Becker muscular dystrophy. ${ }^{17,18}$ Muscular dystrophy occurs in both sexes and in all ages and races. People with a family history of muscular dystrophy are at a higher risk of developing the disease or passing it onto their children. Related to causes of these diseases, certain genes are involved in making proteins that protect muscle fibers from damage. Muscular dystrophy occurs when one of these genes is defective. Each form of muscular dystrophy is caused by a genetic mutation particular to a specific type of the disease. Many of these mutations are inherited. Some, however, occur spontaneously in the mother's egg or the developing embryo and can be passed onto the next generation. ${ }^{19-21}$ Some different methods can be used to diagnose the various types of muscular dystrophy, such as a Serum creatine kinase (CPK) test, an electromyography (EMG) test, a nerve conduction velocity (NCV) test, a genetic test, and a muscle biopsy. Damaged muscles release enzymes, such as creatine kinase, into the blood. In a person who has not had a traumatic injury, high blood levels of CPK suggest a muscle disease, such as muscular dystrophy. In an EMG test, an electrode needle is inserted into the muscle to be tested and changes in the pattern of electrical activity can confirm a muscular disease. In genetic testing, blood samples can be examined for mutations in some of the genes that cause different types of muscular dystrophy. Also, related to a muscle biopsy, a small piece of muscle can be removed through an incision or with a hollow needle. Analysis of the tissue sample can distinguish muscular dystrophies from other muscle diseases. ${ }^{22-24}$ Some dystrophies are especially frequent in certain populations but are rare elsewhere: for example, autosomal dominant distal muscular dystrophy in Scandinavia, Fukuyama muscular dystrophy in Japan, oculopharyngeal muscular dystrophy in French Canada, and several autosomal recessive limb-girdle muscular dystrophies in communities in Brazil, North America, and the Middle East. ${ }^{1,25}$ There are no more studies regarding the prevalence of muscular dystrophy in Iran. This study was aimed to survey the prevalence of muscular dystrophy among Iranian patients with muscular disorders.

\section{Materials and Methods}

The analytical cross-sectional study was conducted on 1000 patients with musculoskeletal disorders who visited the dystrophy association of Bou-Ali Hospital (Tehran) from June 2014 to June 2016. Subjects were selected by convenient sampling. Inclusion criteria were having any type of muscular dystrophy of unknown etiology, an age of less than 60 years, and the absence of systemic musculoskeletal disorders. All subjects were asked to fill a consent form in advance. In the first stage, 1,000 people with muscular dystrophy of unknown etiology were included in the study. After reviewing the medical files, 337 cases were found eligible for further investigation, and the rest were excluded. The data collection tool was a two-part questionnaire: The first part pertained to demographic information (age, gender); the second part was dedicated to clinical information, including the age of onset, family history of disease, findings from clinical diagnostic tests, and the type of dystrophy. The enquired clinical findings were the results of genetic tests; EMG$\mathrm{NCV}$; paraclinical findings, including $\mathrm{LDH}$ and $\mathrm{CPK}$; and pathological findings. Exclusion criteria included any deficiency in a patient's medical records and a patient's refusal to participate. This study was disclosed to and approved by the ethics and research committees of the faculty of medicine of Islamic Azad UniversityTehran Medical Branch. The collected data was analyzed with SPSS V.22 (IBM Inc., NY). The chi-square test was used to quantify the qualitative variables and determine their relationship with dystrophy types and the one-way ANOVA was used to analyze this relationship for twostate quantitative variables. All analyses were performed with $P=0.05$ considered as the threshold of statistical significant.

\section{Results and Discussion}

Out of the 337 patients studied, $262(77.7 \%)$ were male and $75(22.3 \%)$ were female. Subjects had a mean $( \pm$ SD) age of $26.08( \pm 11.86)$ years, with youngest being 3 years old the oldest being 59 years. Analysis of family history of muscular diseases showed that 99 patients $(29.44 \%)$ had a close relative with muscular dystrophy. The mean ( \pm SD) age of onset was $10.52( \pm 7.97)$ years, with the lowest being 1 year and the highest being 38 years. The most common types of muscular dystrophy were found to be Duchenne dystrophy (131 cases, 38.9\%), limbgirdle dystrophy (91 cases, 27\%), Becker dystrophy (58 cases, 17.2\%), FSHD dystrophy (31 cases, 9.2\%), and SMA (26 cases, 7.7\%), in that order. The chi-square test showed that the dystrophy type had a significant relationship with gender and family history of disease $(P$ 
Table 1. Associations between Demographic Variables and Types of Dystrophy

\begin{tabular}{|c|c|c|c|c|c|c|c|c|}
\hline & \multicolumn{7}{|c|}{ Types of Dystrophy } \\
\hline & & $\begin{array}{c}\text { Duchenne } \\
N(\%)\end{array}$ & $\begin{array}{l}\text { Limb- } \\
\text { Girdle } \\
N(\%)\end{array}$ & $\begin{array}{l}\text { Becker } \\
N(\%)\end{array}$ & $\begin{array}{c}\text { Facioscapul } \\
\text { ohumeral } \\
N(\%)\end{array}$ & $\begin{array}{c}\text { Spinal } \\
\text { Muscular } \\
\text { Atrophy } \\
N(\%)\end{array}$ & $\begin{array}{c}\text { Total } \\
N(\%)\end{array}$ & $\begin{array}{c}P \\
\text { value }\end{array}$ \\
\hline \multirow{2}{*}{ Gender } & Male & $127(48.47)$ & $43(16.41)$ & $53(20.22)$ & $22(8.40)$ & $17(6.49)$ & $262(100)$ & \multirow{2}{*}{$\begin{array}{c}P< \\
0.001\end{array}$} \\
\hline & Female & $4(5.33)$ & $48(64)$ & $5(6.66)$ & $9(12)$ & $9(12)$ & $75(100)$ & \\
\hline \multirow{2}{*}{$\begin{array}{l}\text { Family } \\
\text { History }\end{array}$} & Positive & $14(14.14)$ & $43(43.43)$ & $23(23.23)$ & $10(10.10)$ & $9(9.90)$ & 99 (100) & \multirow{2}{*}{$\begin{array}{c}P< \\
0.001\end{array}$} \\
\hline & Negative & $117(49.15)$ & $48(20.16)$ & $35(14.70)$ & $21(8.82)$ & $17(7.14)$ & $238(100)$ & \\
\hline \multirow{6}{*}{$\begin{array}{l}\text { Age of } \\
\text { Patients }\end{array}$} & $0-10$ & $20(83.33)$ & $0(0)$ & $0(0)$ & $0(0)$ & $4(16.66)$ & $24(100)$ & \multirow{6}{*}{$\begin{array}{c}P< \\
0.001\end{array}$} \\
\hline & $10-20$ & $75(72.11)$ & $10(9.61)$ & $12(11.53)$ & $4(3.84)$ & $3(2.88)$ & $104(100)$ & \\
\hline & $20-30$ & $29(31.18)$ & $25(26.88)$ & $20(21.50)$ & $12(12.90)$ & $7(7.52)$ & $93(100)$ & \\
\hline & $30-40$ & $6(7.5)$ & $39(48.75)$ & $17(21.25)$ & $9(11.25)$ & $9(11.25)$ & $80(100)$ & \\
\hline & $40-50$ & $1(4.34)$ & $13(56.52)$ & $3(13.04)$ & $5(21.73)$ & $1(4.34)$ & $23(100)$ & \\
\hline & $50-60$ & $0(0)$ & $4(30.76)$ & $6(46.15)$ & $1(7.7)$ & $2(15.38)$ & $13(100)$ & \\
\hline \multirow{6}{*}{$\begin{array}{c}\text { Age of } \\
\text { Onset }\end{array}$} & $0-10$ & $123(63.40)$ & $23(11.85)$ & $26(13.40)$ & $5(2.57)$ & $17(8.76)$ & $194(100)$ & \multirow{6}{*}{$\begin{array}{c}P< \\
0.001\end{array}$} \\
\hline & $10-20$ & $8(7.84)$ & $44(43.13)$ & $23(22.54)$ & $20(19.60)$ & $7(6.86)$ & $102(100)$ & \\
\hline & $20-30$ & $0(0)$ & $20(55.55)$ & $9(25)$ & $6(16.66)$ & $1(2.77)$ & $36(100)$ & \\
\hline & $30-40$ & $0(0)$ & $4(80)$ & $0(0)$ & $0(0)$ & $1(20)$ & $5(100)$ & \\
\hline & $40-50$ & $0(0)$ & $0(0)$ & $0(0)$ & $0(0)$ & $0(0)$ & $0(0)$ & \\
\hline & $50-60$ & $0(0)$ & $0(0)$ & $0(0)$ & $0(0)$ & $0(0)$ & $0(0)$ & \\
\hline
\end{tabular}

$<$ 0.001) (Table 1). Also, a statistically significant relationship was found between dystrophy type and a patient's age and age of onset $(P<0.001)$. A review of pathologic findings showed that 263 subjects $(78 \%)$ had tested positive in pathological tests and 74 subjects $(22 \%)$ had tested negative. EMG-NCV test results confirmed the presence of muscular dystrophy in 306 patients $(90.8 \%)$. A review of genetic test results showed that genetic evidence confirms the presence of muscular dystrophy in 246 (73\%) patients, but not in the remaining $91(27 \%)$ cases. Analysis of paraclinical findings (CPK and $\mathrm{LDH}$ ) revealed a statically significant relationship between dystrophy type and CPK and LDH levels $(P<$ $0.001)$. The subjects had a mean $( \pm$ SD) $\mathrm{CPK}$ and $\mathrm{LDH}$ of 5182.09 ( \pm 7001.92$) \mathrm{U} / \mathrm{l}$ and $2831.69( \pm 1157.66) \mathrm{U} / \mathrm{l}$, respectively, which were several times higher than normal. Statistical analysis showed no significant relationship between dystrophy type and the pathological findings $(P=0.57)$, EMG-NCV test results $(P=0.062)$, or genetic findings $(P=0.06)$ (Table 2$)$. Our study of 337 patients with muscular dystrophy (who visited Bou-Ali Hospital in Tehran) found the most common types of this disorder to be Duchenne dystrophy, limb-girdle, Becker dystrophy, FSHD dystrophy, and SMA, in that order. The incident of dystrophy was found to have a statistically significant relationship with gender and family history, as it was more prevalent among males than females and also more prevalent among people with a family history of dystrophy. In terms of the prevalence of dystrophy types, our results are consistent with the results of Paul et al., ${ }^{25}$ which showed the higher prevalence of Duchenne dystrophy than Becker dystrophy in the United States, ${ }^{26}$ and with the meta-analysis of Mah et al. ${ }^{26}$ which reported that Duchenne dystrophy is more prevalent than Becker. $^{27}$ In a study by Norwood et al. ${ }^{28}$ on the prevalence of gene-related muscle disorders, the most common types of dystrophy were reported to be myotonic (28.6\%), FSHD (10.7\%), limb-girdle (6.2\%), 
Table 2. Associations between Genetic Tests, Pathology, and EMG-NCV Test Results and Types of Dystrophy

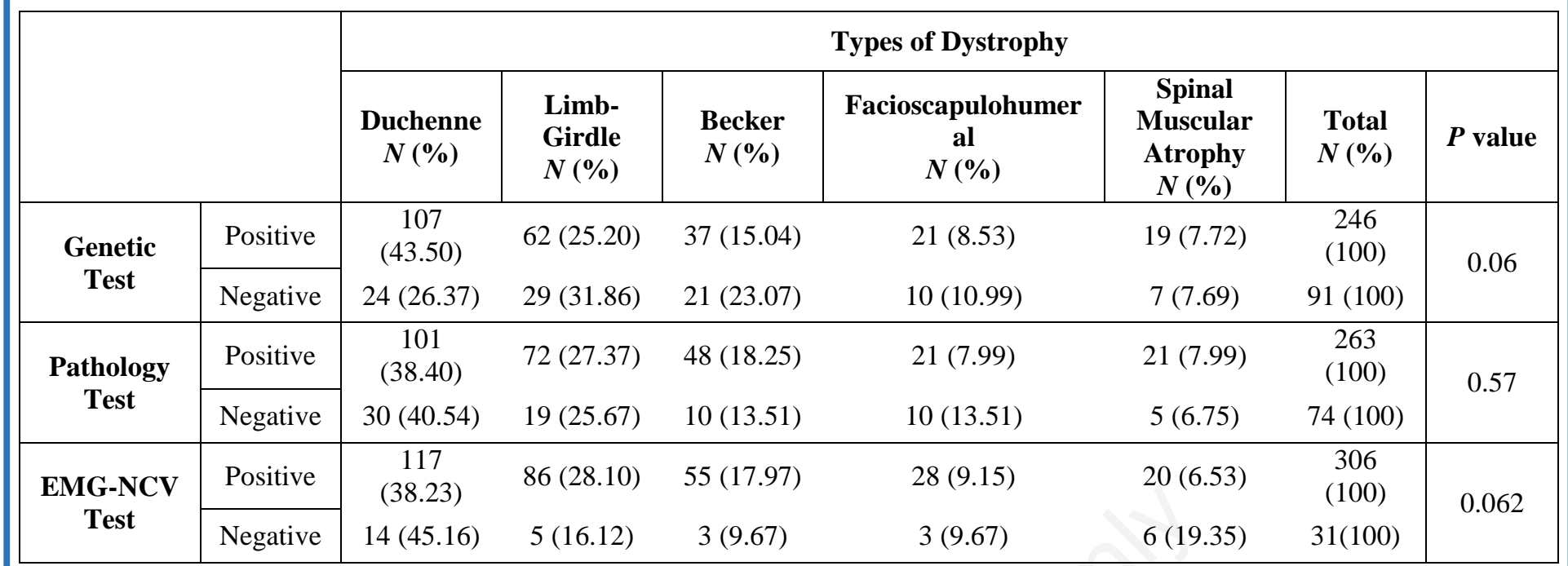

and SMA (5.1\%). In our study, the prevalence of limbgirdle dystrophy was $27 \%$, which is higher than the figure reported by Norwood et al., ${ }^{28}$ but our observations in regard to prevalence of FSHD dystrophy and SMA are largely consistent with their findings. ${ }^{28} \mathrm{~A}$ systematic review of the literature on the prevalence of dystrophy types by Theadom et al. ${ }^{29}$ has also reported that myotonic dystrophy, Duchenne dystrophy, and FSHD dystrophy are the most common types of this disorder. In that study, myotonic dystrophy was reported as the most prevalent type of dystrophy, but our data showed Duchenne dystrophy to be the most common type. ${ }^{29}$ Our results regarding the prevalence of dystrophy types are also consistent with the results of a study by Leth et al., ${ }^{30}$ which showed that Duchenne dystrophy, limb-girdle dystrophy, and FSHD dystrophy are the most common types of dystrophy in Denmark. ${ }^{30}$ In a study by Ballo et al., ${ }^{31} 46 \%$ of people with Duchenne dystrophy and Becker dystrophy had a family history of these disorders. However, in our study, only $29.40 \%$ of subjects had such family history. Also, in Ballo et al.'s study, $60 \%$ of patients who had Becker dystrophy (20 cases) had a positive family history, but in our study, this figure was $40 \%$. This difference is probably due to differences in the sample size and the type of dystrophies examined. ${ }^{31}$ In our study, dystrophy type was found to have a statistically significant relationship with gender, as it was more prevalent among men than women. In this respect, our results are consistent with the results of Dogan et al., ${ }^{32}$ which report that gender can affect dystrophy phenotype and severity and that men are more frequently affected by the disease than women. ${ }^{32} \mathrm{We}$ also found a statistically significant relationship between the age of onset and dystrophy type. Our results showed that, statistically, Duchenne dystrophy appears during the first decade of life (at ages less than 10 years), Becker dystrophy appears during the first and second decades (at ages less than 20 years), FSHD dystrophy appears during the second decade (at ages between 10 and 20 years), limb-girdle dystrophy appears during the first three decades (at ages less than 30 years), and SMA appears during the first decade of life (at ages less than 10 years). In a study by Mahjneh et al., ${ }^{33}$ limb-girdle dystrophy was reported to emerge during the first three decades of life, which is in agreement with our results..$^{33}$ In the study by Ballo et al., ${ }^{32}$ diagnosis of Duchenne dystrophy was confirmed in about $42 \%$ of cases by genetic test results. In our study, this figure was about $73 \%$ for all types of dystrophy and about $81 \%$ for Duchenne dystrophy alone. ${ }^{34}$ In a study by Hallwirth-Pillay et al. ${ }^{34}$ and in a group of 68 patients with Duchenne dystrophy and Becker dystrophy, about $57 \%$ of diagnoses were confirmed by genetic test results, which is lower than the figure obtained in our study. ${ }^{35}$ Also, in a study by Chung et $\mathrm{al}^{35}$ on the prevalence of muscular dystrophy in Chinese children based on the results of genetic and EMG-NCV tests, it was found that $228(68 \%)$ of the 332 studied children had gene-related muscular dystrophies. An epidemiological study by El-Tallawy et al. ${ }^{36}$ on muscular dystrophies in Egypt found that more than 80\% of subjects had an elevated CPK (> $225 \mathrm{IU} / \mathrm{l})$, which is consistent with our results, which showed elevated CPK in about $88.8 \%$ of patients. In this study, we investigated the prevalence of muscular dystrophy in an Iranian population. Duchenne dystrophy, limb-girdle dystrophy, Becker dystrophy, FSHD, and SMA were found to be the most common types of dystrophy among subjects. The results showed a significant relationship between the incident of dystrophy and age, gender, and family history of the disease. Since these dystrophies often appear during the first decade of life, any information in regard to their prevalence can contribute to better planning and 
provisioning of required services, as well as better treatment or control of the condition. The results also showed that genetic tests, paraclinical tests, pathology analysis, and EMG-NCV tests can serve as good diagnostic tools for different varieties of dystrophy. Thus, facilitation of these diagnostic tests, particularly the genetic tests, can lead to a faster and more accurate diagnosis of dystrophy, especially in people with a family history of the disease.

\section{List of acronyms}

SMA - Muscular atrophy

FSHD - Facioscapulohumeral or

CPK - Serum creatine kinase

EMG - Electromyography

$\mathrm{NCV}$ - nerve conduction velocity

\section{Author's contributions}

Each author contributed in equal part to the manuscript.

\section{Acknowledgments}

This research received no specific grant from any funding agency in the public, commercial or not-for-profit sectors.

\section{Conflict of Interest}

The authors declare no conflicts of interests.

\section{Ethical Publication Statement}

We confirm that we have read the Journal's position on issues involved in ethical publication and affirm that this report is consistent with those guidelines.

\section{Corresponding Author}

Khadijeh Haji Naghi Tehrani, Department Neurology, Islamic Azad University, Tehran Medical Sciences Branch, Tehran, Iran. Phone 00989121493324

Email: Dr_tehrani10@yahoo.com

\section{E-mail of co-authors}

Maliheh Hajiloo: malihehajiloo@yahoo.co.uk Elham Asadollahi: e.asadolahi90@gmail.com Fariba Paydar Lagini: faribapd59@yahoo.com

\section{References}

1. Emery AE. The muscular dystrophies. Lancet 2002;359:687-95.

2. Mercuri E, Muntoni F. Muscular dystrophies. Lancet 2013;381:845-60.

3. Emery AEH, Dreifuss FE. Unusual type of benign X-linked muscular dystrophy. J Neurol Neurosurg Psychiatry 1966;29:338-42.

4. Understanding Muscular Dystrophy - the Basics. WebMD. Available at: http://www.webmd.com/ children/understanding-muscular-dystrophybasics\#2 [Accessed 14 Aug. 2017].

5. Emery AEH. Duchenne muscular dystrophy. 2nd edn. Oxford University Press, Oxford; 1993.
6. Becker, PE, Kiener, F. Eine neue X-chromosomale muskeldystrophie. Arch Psychiatr Nervenkrank heiten 1955;193:427-48

7. Hoffman, EP, Brown, RH, Kunkel LM. Dystrophin: the protein product of the Duchenne muscular dystrophy locus. Cell 1987;51:919-28.

8. Darras BT. Treatment of Duchenne and Becker muscular dystrophy. http://www.uptodate.com /home Accessed Oct. 23, 2014.

9. Abresch RT. Exercise in neuromuscular diseases. Physical Medicine \& Rehabilitation Clinics of North America 2012;23:653.

10. Benditt JO. Pulmonary issues in patients with chronic neuromuscular disease. American Journal of Respiratory and Critical Care Medicine 2013; 187:1046.

11. Becker, PE, Kiener, F. Eine neue X-chromosomale muskeldystrophie. Arch Psychiatr Nervenkrank heiten. 1955;193 427-48.

12. Becker, PE. Two new families of benign sex-linked recessive muscular dystrophy. Rev Can Biol 1962;21:551-66.

13. Laforêt, P, Eymard, B, Becane, HM, et al. Cardiac involvement in facioscapulohumeral muscular dystrophy: the experience of the Salpêtrière Hospital in 2001 (Abstract). Neuromuscul Disord 2001;11:616-17.

14. Brais, B, Rouleau, GA, Bouchard, JP, et al. Oculopharyngeal muscular dystrophy. Semin Neurol 1999;19:59-66.

15. Brais, B, Bouchard, JP, Xie, YG, et al. Short GCG expansions in the PABP2 gene cause oculopharyngeal muscular dystrophy. Nat Genet 1998;18:164-67.

16. Bushby, KMD. The limb-girdle muscular dystrophies. In: Emery AEH (Ed.) The muscular dystrophies. Oxford University Press, Oxford; 2001, p.p. 109-36.

17. Darin N, Tulinius M. Neuromuscular disorders in childhood: a descriptive epidemiological study from western Sweden. Neuromuscular disorders: NMD 2000;10:1-9.

18. Andersson PB, Rando TA. Neuromuscular disorders in childhood. Curr Opin Pediatr 1999;11:497-503.

19. Darras BT. Myotonic dystrophy: Etiology, clinical features, and diagnosis. http://www.uptodate. com/home. Accessed Oct. 24, 2014.

20. Darras BT. Treatment of Duchenne and Becker muscular dystrophy. http://www.uptodate.com /home. Accessed Oct. 23, 2014.

21. Darras BT. Patient information: Overview of muscular dystrophies (beyond the basics). http://www.uptodate.com/home. Accessed Oct. 23, 2014.

22. Van Ommen, GJB, Scheuerbrandt, G. Workshop report: neonatal screening for muscular dystrophy. Neuromuscul Disord 1993;3:231-39. 


\section{Muscular Dystrophy}

Eur J Transl Myol 28 (2): 220-225, 2018

23. Bushby, K, Hill, A, Steele, JG. Failure of early diagnosis in symptomatic Duchenne muscular dystrophy. Lancet 1999; 353:557-58.

24. Sewry, CA, Brown, SC, Mercuri, E. Skeletal muscle pathology in autosomal dominant EmeryDreifuss muscular dystrophy with lamin A/C mutations. Neuropathol Appl Neurobiol 2001;27:281-90.

25. Darin, N and Tulinius, M. Neuromuscular disorders in childhood: a descriptive epidemiological study from western Sweden. Neuromuscul Disord 2000;10:1-9.

26. Romitti PA, Zhu Y, Puzhankara S, et al. Prevalence of Duchenne and Becker muscular dystrophies in the United States. Pediatrics 2015;135:513-21.

27. Mah JK, Korngut L, Dykeman J, et al. A systematic review and meta-analysis on the epidemiology of Duchenne and Becker muscular dystrophy. Neuromuscular disorders: NMD 2014;24:482-91.

28. Norwood FL, Harling C, Chinnery PF, et al. Prevalence of genetic muscle disease in Northern England: in-depth analysis of a muscle clinic population. Brain 2009;132:3175-86.

29. Theadom A, Rodrigues M, Roxburgh R, et al. Prevalence of muscular dystrophies: a systematic literature review. Neuroepidemiology 2014;43:259-68.

30. Leth A, Wulff K, Corfitsen M, et al. Progressive muscular dystrophy in Denmark. Natural history, prevalence and incidence. Acta Paediatr Scand 1985; 74:881-5.

31. Ballo R, Viljoen D, Beighton P. Duchenne and Becker muscular dystrophy prevalence in South Africa and molecular findings in 128 persons affected. S Afr Med J 1994;84:494-7.

32. Dogan C, De Antonio M, Hamroun D, Varet H, Fabbro M, Rougier F. Gender as a Modifying Factor Influencing Myotonic Dystrophy Type 1 Phenotype Severity and Mortality: A Nationwide Multiple Databases Cross-Sectional Observational Study. PloS one 2016;11:e0148264.

33. Mahjneh I, Bushby K, Pizzi A, et al. Limb-girdle muscular dystrophy: a follow-up study of 79 patients. Acta Neurol Scand 1996; 94:177-89.

34. Hallwirth Pillay KD, Bill PL, Madurai S, et al. Molecular deletion patterns in Duchenne and Becker muscular dystrophy patients from KwaZulu Natal. J neurolssci 2007;252:1-3.

35. Chung B, Wong V, IP P. Prevalence of neuromuscular diseases in Chinese children: a study in southern China. J Child Neurol 2003; 18:217-9.

36. El-Tallawy HN, Khedr EM, Qayed MH, et al. Epidemiological study of muscular disorders in Assiut, Egypt. Neuroepidemiology 2005;25:205-11.

Submission: 27/02/18

Revisions received: 05/04/18

Acceptance: 07/04/18 